\title{
Prevalence of dementia and its associated risk factors among elderly patient attending Outpatient Department of a tertiary care hospital in Lucknow
}

\section{Rashmi Kumari ${ }^{1}$, Arvind Kumar Singh ${ }^{2}$, Amit Kaushik ${ }^{3}$, Tanya Thakker ${ }^{4}$, Shikhar Singh ${ }^{5}$, Sunil Dutt Kandpal ${ }^{6}$}

${ }^{1}$ Assistant Professor, Department of Community Medicine, Dr Ram Manohar Lohia Institute of Medical Sciences, Lucknow , Uttar Pradesh; ${ }^{2}$ Associate Professor, Department of Community Medicine, Dr Ram Manohar Lohia Institute of Medical Sciences, Lucknow , Uttar Pradesh; ${ }^{3}$ Associate Professor, Department of Community Medicine, Dr Ram Manohar Lohia Institute of Medical Sciences, Lucknow, Uttar Pradesh; ${ }^{4}$ MBBS Student, Dr Ram Manohar Lohia Institute of Medical Sciences, Lucknow , Uttar Pradesh ${ }^{5}$ Senior Resident, ${ }^{6}$ Professor \& Head, Department of Community Medicine, Dr Ram Manohar Lohia Institute of Medical Sciences, Lucknow, Uttar Pradesh

\begin{tabular}{|c|c|c|c|c|c|c|c|c|}
\hline Abstract & Introduction & Methodology & Results & Conclusion & References & Citation & \multicolumn{2}{|c|}{ Tables / Figures } \\
\hline \multicolumn{9}{|c|}{ Corresponding Author } \\
\hline \multicolumn{8}{|c|}{$\begin{array}{l}\text { Dr Rashmi Kumari, Department of Community Medicine, Dr Ram Manohar Lohia Institute of Medical } \\
\text { Sciences, Lucknow, Uttar Pradesh } 226010 . \\
\text { E Mail ID: } \underline{\text { rashmidmch2k@gmail.com }}\end{array}$} & 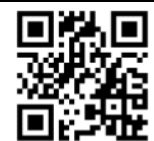 \\
\hline
\end{tabular}

\section{Citation}

Kumari R, Singh A K, Kaushik A, Thakker T, Singh S, Kandapl S D. Prevalence of dementia and its associated risk factors among elderly patient attending Outpatient Department of a tertiary care hospital in Lucknow. Indian J Comm Health. 2021;33(2):276-281. https://doi.org/10.47203/IJCH.2021.v33i02.009

Source of Funding: Indian Council of Medical Research, STS Conflict of Interest: None declared

\section{Article Cycle}

Received: 18/01/2021; Revision: 11/04/2021; Accepted: 02/05/2021; Published: 30/06/2021

This work is licensed under a Creative Commons Attribution 4.0 International License.

\section{Abstract}

Background: Dementia is a broad category of brain diseases that causes a chronic, progressive and gradual decrease in cognitive function i.e. ability to think and remember that is great enough to affect a person's daily functioning beyond what might be expected from normal ageing. According to American Psychiatric Association, "Dementia is a syndrome caused by a variety of brain illnesses that affect memory, thinking, behaviour and the ability to perform everyday activities". Aim \& Objectives: To assess the prevalence of dementia among the patients above 60 years of age attending the outpatient department of Tertiary care super specialty hospital. To assess the risk factors associated with occurrence of dementia in patients attending outpatient department of Tertiary care super specialty hospital. Settings and Design: Study design: - Crosssectional observational study. Study area: - Tertiary care super-specialty hospital. Study setting: - Outpatient department (OPD)of Tertiary care super specialty hospital. Methods and Material: Study population: - Patients above 60 years of age and attending Outpatient Department of the tertiary care super specialty hospital. Duration of Study: - 4 months. Sample size:223 elderly participants from the registration counter of the Outpatient Department of tertiary care hospital. Statistical analysis used: Data was analysed using SPSS, version 24.0. Univariate Logistic Regression, Multivariate Logistic Regression, Odds Ratio. Results: The study was conducted on a total of 223 patients out of which only 210 patients completed the questionnaire and matched our criteria. Thus, 210 patients are analysed for the result. In our study which included the patients above 60 years of age out of which the maximum participants (52.4\%) were of age group $65-75$. In our study $66.2 \%$ participants had normal cognitive functioning while $33.8 \%$ of total participants were found to have dementia. Out of these $33.8 \%$ participants having impaired cognitive functioning, $13.8 \%$ and $20 \%$ had severe and borderline dementia respectively. Dementia was found to be more common in females. Conclusions: Statistically significant association of dementia has been found with female gender, rural residence, joint family and a greater number of family members, poor education, pan masala consumption, daytime drowsiness, and problem in sleep pattern, social intolerance and frequent fights.

\section{Keywords}

Dementia; Cognitive Function; Elderly; Tertiary Care.

\section{Introduction}

As life expectancy is increasing more population is becoming older. This increase in life expectancy leads to increase in health problem related to age. One of the major health problems of old age is dementia. Dementia which is a broad category of brain diseases that causes a chronic, progressive and gradual decrease in cognitive 
function i.e. ability to think and remember that is great enough to affect a person's daily functioning beyond what might be expected from normal ageing $(1,2)$. There are various types of dementia like Alzheimer's disease, vascular dementia, Lewy body dementia, frontotemporal dementia, Parkinson's $(1,3)$

According to WHO around the world around 50 million people have dementia with yearly increase of 10 million cases leading to disability, which is further projected to increase to 82 million in 2030 and 152 by 2050 . Prevalence of dementia increase with age and among people above 60 year of age the prevalence of dementia varies from 5 percent to 8 percent $(1,4)$.

In India around approximately 2 to 4 million to people are suffering from various forms of dementia(4). Various study has shown the prevalence of dementia varies from 0.84 percent 8.04 percent depending upon study area and study setting. In rural areas of south India prevalence was 3.34 and urban area prevalence was 2.4 percent whereas in north India prevalence 0.84 percent in rural area and 1.84 percent in urban area(5-10). Among all the dementias, Alzheimer's disease is the most common around the world contributing 60 to 80 percent of all the cases $(1,5)$.

Some of the risk factors assumed to be associated with dementia are Age, Genetics/family history, Smoking and alcohol use, Atherosclerosis, Cholesterol, Plasma homocysteine, Diabetes, Mild cognitive impairment, high blood pressure, obesity, hearing loss, Anticholinergic drugs used for depression, chronic obstructive pulmonary disease, overactive bladder, allergies, and gastrointestinal disorders $(1,11)$.

For diagnosis of Dementia usually made clinically with help of mental state examination, laboratory investigations and neuro-imagery(11). There are many tools for screening of dementia most notably MMSE which is a validated tool in English with Hindi translation.

As there is paucity of research in India, regarding the prevalence of dementia. So current study was planned with objectives to assess the prevalence of dementia among the patients above 60 years of age attending the outpatient department of Tertiary care super specialty hospital.

\section{Aims \& Objectives}

1. To assess the prevalence of dementia among the patients above 60 years of age attending the outpatient department of Tertiary care super specialty hospital.

2. To assess the risk factors associated with occurrence of dementia in patients attending outpatient department of Tertiary care super specialty hospital

\section{Material \& Methods}

A Cross-sectional study was conducted at Outpatient department of Tertiary care super-specialty hospital among patients above 60 years of age over a period of 4 months between July 2019 to October 2019. Previous research suggested the prevalence of dementia of $8.04 \%$ in similar setting(10). Assuming similar prevalence in our study sample size was calculated 202 at Confidence interval at $95 \%$ with assumed error of 4 percent. Assuming $10 \%$ patients not consenting to interview (dropout rate) it was decided to sample 223 elderly participants from the registration counter of the Outpatient Department of tertiary care hospital. The tertiary care hospital selected for conduction of this study had a central computer-based Outpatient registry kiosk. The first 10 patients registered at outpatient registry kiosk fulfilling the inclusion and exclusion criteria and aged $>60$ years were included consecutively. To cover required sample size of 223 , it was decided to conduct data collection for 25 working days. The patients hence selected were approached for their willingness to be part of the study; only those patients who gave consent and were above 60 years of age and attending the Outpatient Department were included in the study. Those Patients who were above 60 years of age and attending the Out-Patient Department but were not fit for interview were excluded. Thus 210 patients who gave consent and matched our inclusion and exclusion criteria were included in the study. Data was collected using Self-design questionnaire containing question regarding Bio Social Characteristics and various risk factors and Hindi Mental State Examination (HMSE) which is a validated screening and diagnostic tool for detecting Impaired cognitive function(dementia) with high specificity, sensitivity irrespective of literacy status of patients. HMSE was graded as 23-30 = normal, 19-23 = borderline Dementia, and $<19=$ Severe Dementia (12). Ethical approval was taken from the institute ethical committee numbered IEC No.97/18 before starting of data of collection.

Data was analyzed using SPSS, version 24.0 licensed to Dr. RMLIMS. Descriptive summary such as mean, standard deviation for continuous variable, frequencies percentage for categorical variables were determined. Proportions, graphs and cross tabs were used to present study results. Univariate logistic regression analysis was done for finding predictors and odds ratio and those which came significant were included in multivariate regression (enter method) for predictors with adjusted odds ratios at 95 percent confidence interval.

\section{Results}

The study was conducted on a total of 223 patients out of which only 210 patients completed the questionnaire and matched our criteria. Thus, 210 patients are analyzed for the result. In our study which included the patients above 60 years of age out of which the maximum participants (52.4\%) were of age group 65-75. Mean age of distribution is $69.36 \pm 6.38$. Majority participants $(63.8 \%)$ constituted male patients. $75.2 \%$ patients were old patients with previously started treatment in the hospital.88.6\% of the 
total participants were Hindu and $64.8 \%$ were of general category.52.5\% participants live in urban areas. Also, $69.5 \%$ participants were from joint families. Majority (63.3\%) patients were with no parental history of dementia as shown in [Table 1].

In our study $66.2 \%$ of participants had normal cognitive functioning while $33.8 \%$ of total participants were found to have dementia out of these $33.8 \%$ participants having impaired cognitive functioning, $13.8 \%$ and $20 \%$ had severe and borderline dementia respectively as shown in [Figure 1].

[Table 2] shows distribution of various factors according to dementia status. Among people aged more than $75 \mathrm{yrs}$. had 43.4 percent had dementia. 57.9 percent of female patients had dementia whereas $79.9 \%$ male didn't had dementia, 45.8 percent of Muslims had dementia whereas among Hindus 32.8 percent had cognitive impairment. patient belonging to general cast 63.2 percent did not had dementia According to area of residence, $42 \%$ of patients from rural residence presented with dementia. Type of family, of all the participants from joint family $41.8 \%$ had dementia. It has also been noticed that as the number of family members increase, the prevalence of dementia increases. Participants when asked to rate their educations, $83 \%$ of those giving least rates to their education were found to have dementia and $96.2 \%$ patient with very good rating didn't had dementia. Patients which were physically active (exercising more than $30 \mathrm{~min}$ ) 71.4 percent were not sufferings from cognitive impairment. Among people who using substance like tobacco (smoked), alcohol, pan masala, tobacco (chewed) marijuana/bhang had 28.6 percent, 37.9 percent, 23.7 percent 42.1 percent, 75 percent were having impaired cognition. Nutritional status according to BMI (WHO classification), among patient who were overweight (BMI $\geq 25.0$ ) 75.0 percent didn't had dementia. 48 percent who had poor sleep quality on self-rating had cognitive impairment

[Table 3] and [Figure 2] shows Multivariate analysis of various factors for Dementia which were found to be significant on univariate analysis. Patients who were female, living in joint family, poor/average educational rating, physical inactivity, average/poor/very poor sleep quality and suffering from depression had 2.3, 3.4, 5.5, 3.1, 2.4 and 5.3 times more chances of developing dementia respectively.

\section{Discussion}

The study was conducted on a total of 223 patients out of which only 210 patients

completed the questionnaire and matched our criteria. Among those Majority participants (63.8\%) constituted male patients. $75.2 \%$ patients were old patients with previously started treatment in the hospital.88.6\% of the total participants were Hindu and $64.8 \%$ were of general category.52.5\% participants live in urban areas. Also,
$69.5 \%$ participants were from joint families. Majority (63.3\%) patients were with no parental history of dementia. Our study found that the overall prevalence of dementia in OPD of tertiary care hospital was $33.8 \%$, out of which $20 \%$ participants had borderline dementia and $13.8 \%$ had severe dementia. This contrasts with the study conducted by Mahesh Kumar Mummadi (11) entitled "A cross-sectional study on dementia in elderly persons living in old-age homes of Hyderabad, Telangana" found that the prevalence of severe dementia was $8.04 \%$. while the studies by Dominguez J et.al. (13) and Li Yang et.al. (14) which the conducted in Philippines and china respectively, found the prevalence of dementia to be $10.6 \%$ and $13 \%$ respectively. The higher values of prevalence of dementia in our study may be due to the above-mentioned studies were normal population-based studies while our study was conducted in a tertiary care hospital which includes a larger fraction of people with various diseased conditions including dementia. Current study found out significant association of dementia with gender as dementia was found to be more common in females. This observation was similar to the studies done in India by Jishnu S. Lalu et.al. (15) and Vas CJ et.al. (16) they also found out that dementia to be more common in females which is mainly due to ApoE-4gene that increases the risk of Alzheimer's. In this study we found the significant association of dementia with rural residence has been found in our study as well as that performed by S Rajkumar et. al.(17) which can be due to poor education and difficulty in understanding the HMSE questions leading to low scores. Dementia has also been found to be more common in people with joint family and a greater number of family members. This is similar to the results of study by Lalu et.al.(15) done in 2018 in urban part of India. The association of dementia with poor education has also been statistically significant in our study as well as those performed by Mahesh Kumar Mummadi (11) and Li Yang et.al.(14) this may be due to higher level of education compensate for the effects of dementia. Statistically significant relationship between dementia and sleep quality has been found in this study. As these are Behavioral and Psychological Symptoms of Dementia (BPSD) which shows that these are the symptoms of dementia and thus are associated with dementia patients. The consumption of depression medication is also associated with dementia. This is similar to the results of study entitled "Anticholinergic drugs and risk of dementia: case-control study" by Kathryn Richardson et.al.(18). It found that anticholinergic drugs that block a chemical messenger called acetylcholine, which affects muscle activity in the digestive and urinary tracts, lungs, and elsewhere in the body is also involved in memory and learning and cause brain inflammation. eg: amitriptyline, paroxetine, and bupropion (most commonly taken for depression) and thus the medications are found to be associated with dementia. 


\section{Conclusion}

The study has concluded that the total prevalence of dementia was $33.8 \%$ in the participants with $20 \%$ of them with borderline dementia and $13.8 \%$ with severe dementia. There is high prevalence of Dementia among elderly attending OPD of all the department not just Neurology department, so there is requirement for better screening services in hospitals for early detection of dementia. Further specialized dementia clinic should be there in tertiary care hospitals for management of dementia, they should provide holistic care to the dementia patient ranging from diagnosis, medical management, psychological therapy and counselling to the attendant of patients.

As demography of India is changing there will be high number of elderly people in India in future, which may lead to high number of dementia patients. So, to tackle that government should take initiatives to establish hospice care centres for proper management of dementia patients. Dementia has also been found to be significantly statistically associated on multivariate analysis with female gender, joint family and a greater number of family members, poor education, pan masala consumption, daytime drowsiness, problem in sleep pattern, physical inactivity poor sleep quality and depression. While other risk factors taken into consideration were not found to have any major effect on prevalence of dementia like caste, religion, smoking, alcohol consumption, tobacco, marijuana/ganja /bhang. All the modifiable risks factors should be controlled so that there is reduction in dementia occurrence.

\section{Recommendation}

Emphasis to be given for geriatric patients for increasing trend of dementia with better facilities for management and treatments in hospitals.

\section{Limitation of the study}

Above study is done at OPD of superspeciality hospital.So patients came here for consultation of their complains. So the finding of above study can't be generalized to general population.

\section{Relevance of the study}

As the demography of India keep changing. Now more than $9 \%$ of the population are above 60 years of age. Dementia is common problem in patients above 60 years. If Screening facility available at geriatric clinic then dementia will get diagnosed early and treatment started.

\section{Authors Contribution}

RK: Conception and design, drafting the article, AKS: revising it critically for important intellectual content, AK: Final approval of the version to be published, TT: acquisition of data, or analysis and interpretation of data, SS: analysis and interpretation of data, SDK: Final approval of the version to be published.

\section{Acknowledgement}

The authors gratefully acknowledge the support from Consultant and residents of Neurology department, Entire OPD Staff for their constant support.

\section{References}

1. Dementia. Who.int.2019. Available from: https://www.who.int/news-room/fact-sheets/detail/dementia (Last Accessed on 25.06.2021)

2. Living well with dementia. Available from: https://www.apa.org/helpcenter/living-with-dementia.

3. Burns A, lliffe S. Dementia. BMJ. 2009;338:b75-b75.

4. Nichols E, Szoeke CEI, Vollset SE, Abbasi N, Abd-Allah F, Abdela J, et al. Global, regional, and national burden of Alzheimer's disease and other dementias, 1990-2016: a systematic analysis for the Global Burden of Disease Study 2016. Lancet Neurol. 2019;18(1):88-106.

5. Das SK, Pal S, Ghosal MK. Dementia: Indian scenario. Neurol India 2012;60:618-624 Available from: http://www.neurologyindia .com/text.asp?2012/60/6/618/105197

6. Das SK, Biswas A, Roy J, Bose P, Roy T, Banerjee TK, et al. Prevalence of major neurological disordersamong geriatric population in the metropolitan city of Kolkata. J Assoc Physicians India 2008;56:17581.

7. Banerjee TK, Mukherjee CS, Dutta A, Shekhar A, Hazra A. Cognitive dysfunction in an urban Indian population- some observations. Neuroepidemiology 2008;31:109-14.

8. Shaji S, Promodu K, Abraham T, Roy KJ, Verghese A. An epidemiological study of dementia in a rural community of Kerala, India Br J Psychiatry 1996;168:745-9.

9. Chandra V, Ganguli M, Pandav R, Johnston J, Belle S, DeKosky ST. Prevalence of Alzheimer's disease and other dementias in rural India: The Indo-US study. Neurology 1998;51:1000-8

10. Mummadi M. A cross-sectional study on dementia in elderly persons living in old-age homes of Hyderabad, Telangana. International Journal of Medical Science and Public Health. 2018;7(11):709

11. Jameson J, Fauci A, Kasper D, Hauser S, Longo D, Loscalzo J. Harrison's principles of internal medicine. 20th ed. New York [etc.] McGraw-Hill Education; 2018.

12. Tsolaki M, lakovidou V, Navrozidou H, Aminta M, Pantazi T, Kazis A. Hindi Mental State Examination (HMSE) as a screening test for illiterate demented patients. International Journal of Geriatric Psychiatry. 2000; 15(7):662-664.

13. Dominguez J, Fe de Guzman $M$, Reandelar M, Thi Phung T. Prevalence of Dementia And Associated Risk Factors: A Population-Based Study in the Philippines. Journal of Alzheimer's Disease. 2018;63(3):1065-1073.

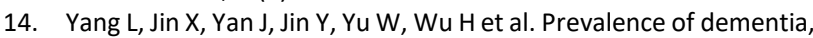
cognitive status and associated risk factors among elderly of Zhejiang province, China in 2014. Age and Ageing. 2016;45(5):707710.

15. Lalu, J., Vijayakumar, P., George, S., Nair, A., \& B., A.. Risk factors of dementia: a comparative study among the geriatric age group in Ernakulam, Southern India. International Journal Of Community Medicine And Public Health, 218;5(2),544-549. doi:http://dx.doi.org/10.18203/2394-6040.ijcmph20180117

16. Vas CJ, Pinto C, Panikker D, Noronha S, Deshpande N, Kulkarni L, et al.Prevalence of Dementia in an Urban Indian Population. International Psycho geriatrics. Cambridge University Press;2001; 13(4):439-50.

17. Rajkumar S, Kumar S, Thara R. Prevalence of Dementia In A Rural Setting: A Report From India. International Journal of Geriatric Psychiatry. 1997;12(7):702-707.

18. Richardson K, Fox C, Maidment I, Steel N, Loke Y, Arthur A et al. Anticholinergic Drugs and risk of dementia: case-control study. BMJ 2018;::k1315. 
Tables

TABLE 1 DISTRIBUTION OF PARTICIPANTS BY SOCIO-DEMOGRAPHIC PROFILE

\begin{tabular}{|c|c|c|c|}
\hline \multicolumn{2}{|c|}{ Categories } & \multirow{2}{*}{$\begin{array}{c}\text { Number of patients(N) } \\
47\end{array}$} & \multirow{2}{*}{$\begin{array}{c}\text { Percentage (\%) } \\
22.4\end{array}$} \\
\hline Age & $<65$ & & \\
\hline & $65-75$ & 110 & 52.4 \\
\hline & $\geq 75$ & 53 & 25.2 \\
\hline \multicolumn{2}{|c|}{ Age (Mean \pm SD) } & \multicolumn{2}{|c|}{$69.36 \pm 6.38$} \\
\hline \multirow[t]{2}{*}{ Gender } & Male & 134 & 63.8 \\
\hline & Female & 76 & 36.2 \\
\hline \multirow[t]{2}{*}{ Type of patient } & Old & 158 & 75.2 \\
\hline & New & 52 & 24.8 \\
\hline \multirow[t]{2}{*}{ Religion } & Hindu & 186 & 88.6 \\
\hline & Muslim & 24 & 11.4 \\
\hline \multirow[t]{3}{*}{ Caste } & General & 136 & 64.8 \\
\hline & $\mathrm{OBC}$ & 62 & 29.5 \\
\hline & SC & 12 & 5.7 \\
\hline \multirow[t]{2}{*}{ Area of residence } & Urban & 110 & 52.4 \\
\hline & Rural & 100 & 47.6 \\
\hline \multirow[t]{2}{*}{ Type of family } & Nuclear & 64 & 30.5 \\
\hline & Joint & 146 & 69.5 \\
\hline \multirow{2}{*}{$\begin{array}{l}\text { Parental History of } \\
\text { dementia }\end{array}$} & Yes & 77 & 36.7 \\
\hline & No & 133 & 63.3 \\
\hline
\end{tabular}

TABLE 2 ASSOCIATION OF STATUS OF COGNITIVE FUNCTION WITH SOCIO-DEMOGRAPHIC PROFILE

\begin{tabular}{|c|c|c|c|}
\hline \multicolumn{2}{|c|}{ Categories } & Dementia present $\mathrm{N}(\%)$ & Dementia absent $\mathbf{N}(\%)$ \\
\hline \multirow[t]{3}{*}{ Age } & $<65$ & $15(31.9)$ & $32(68.1)$ \\
\hline & $65-75$ & $33(30.0)$ & $77(70.0)$ \\
\hline & $>75$ & $23(43.4)$ & $30(56.6)$ \\
\hline \multirow[t]{2}{*}{ Gender } & Male & $27(20.1)$ & $107(79.9)$ \\
\hline & Female & $44(57.9)$ & $32(42.1)$ \\
\hline \multirow[t]{2}{*}{ Religion } & Hindu & $60(32.3)$ & $126(67.7)$ \\
\hline & Muslim & $11(45.8)$ & $13(54.2)$ \\
\hline Area of & Urban & $29(26.4)$ & $81(73.6)$ \\
\hline Residence & Rural & $42(42.0)$ & $58(58.0)$ \\
\hline \multirow[t]{2}{*}{ Type of family } & Nuclear & $10(15.6)$ & $54(84.4)$ \\
\hline & Joint & $61(41.8)$ & $85(58.2)$ \\
\hline Self - & Very bad & $38(83.0)$ & $8(17.0)$ \\
\hline Educational & Bad & $9(30.0)$ & $21(70.0)$ \\
\hline \multirow[t]{3}{*}{ rating } & Average & $17(25.0)$ & $51(75.0)$ \\
\hline & Good & $5(12.8)$ & $34(87.4)$ \\
\hline & Very good & $1(3.8)$ & $25(96.2)$ \\
\hline \multirow[t]{2}{*}{ Physical activity } & Inactive (<30 min) & $31(44.3)$ & $39(55.7)$ \\
\hline & Active (>30 min) & $40(28.6)$ & $100(71.4)$ \\
\hline \multirow[t]{2}{*}{ Nutritional status* } & Normal/underweight & $47(41.2)$ & $67(58.8)$ \\
\hline & overweight & $24(25.0)$ & $72(75.0)$ \\
\hline \multirow[t]{5}{*}{ Sleep quality } & Very poor & $26(48.1)$ & $28(51.9)$ \\
\hline & Poor & $10(31.3)$ & $22(68.8)$ \\
\hline & Average & $17(36.2)$ & $30(63.8)$ \\
\hline & Good & $11(22.0)$ & $39(78.0)$ \\
\hline & Very Good & $7(25.9)$ & $20(74.1)$ \\
\hline \multirow[t]{2}{*}{ Depression } & Yes & $10(58.8)$ & $7(41.2)$ \\
\hline & No & $61(31.6)$ & $132(68.4)$ \\
\hline
\end{tabular}




\begin{tabular}{|c|c|c|c|c|c|c|}
\hline \multirow[t]{3}{*}{ Variable } & \multicolumn{3}{|l|}{ Univariate Analysis } & \multicolumn{3}{|c|}{ Multivariate Analysis } \\
\hline & \multirow[t]{2}{*}{ Odds Ratio (OR) } & \multicolumn{2}{|l|}{$95 \% \mathrm{Cl}$} & \multirow{2}{*}{$\begin{array}{l}\text { Adjusted Odds } \\
\text { Ratio (AOR) }\end{array}$} & \multicolumn{2}{|l|}{$95 \% \mathrm{Cl}$} \\
\hline & & Lower Limit & Upper Limit & & Lower Limit & Upper Limit \\
\hline \multicolumn{7}{|l|}{ Overweight } \\
\hline Yes & 0.475 & 0.262 & 0.86 & - & - & - \\
\hline No & Reference & & & & & \\
\hline \multicolumn{7}{|l|}{ Gender } \\
\hline Female & 5.45 & 2.92 & 10.13 & 2.302 & 1.01 & 5.26 \\
\hline Male & Reference & & & & & \\
\hline \multicolumn{7}{|l|}{ Place of Residence } \\
\hline Rural area & 2.02 & 1.13 & 3.61 & - & - & - \\
\hline Urban area & Reference & & & & & \\
\hline \multicolumn{7}{|l|}{ Type of Family } \\
\hline Joint & 3.87 & 1.83 & 8.2 & 3.433 & 1.43 & 8.26 \\
\hline Nuclear & Reference & & & & & \\
\hline \multicolumn{7}{|c|}{ Education Performance Grading (self)/ Satisfied with Academic Performance } \\
\hline Poor/average & 7.9 & 4.15 & 15.07 & 5.57 & 2.43 & 12.73 \\
\hline Good/ Very good & Reference & & & & & \\
\hline \multicolumn{7}{|l|}{ Pan masala } \\
\hline Yes & 0.51 & 0.26 & 1 & - & - & - \\
\hline No & Reference & & & & & \\
\hline \multicolumn{7}{|l|}{ Physical Inactive } \\
\hline Yes $<30 \mathrm{~min}$ & 1.98 & 1.09 & 3.61 & 3.06 & 1.42 & 6.6 \\
\hline No $>30 \mathrm{~min}$ & Reference & & & & & \\
\hline \multicolumn{7}{|l|}{ Sleep Quality } \\
\hline $\begin{array}{l}\text { Average/Poor/ very } \\
\text { Poor }\end{array}$ & 2.17 & 1.15 & 4.08 & 2.38 & 1.04 & 5.43 \\
\hline Good/ Very good & Reference & & & & & \\
\hline \multicolumn{7}{|l|}{ Depression } \\
\hline Yes & 3.09 & 1.12 & 8.5 & 5.29 & 1.35 & 20.78 \\
\hline No & Reference & & & & & \\
\hline
\end{tabular}

\section{Figures}

\section{FIGURE 1 PREVALENCE OF DEMENTIA}

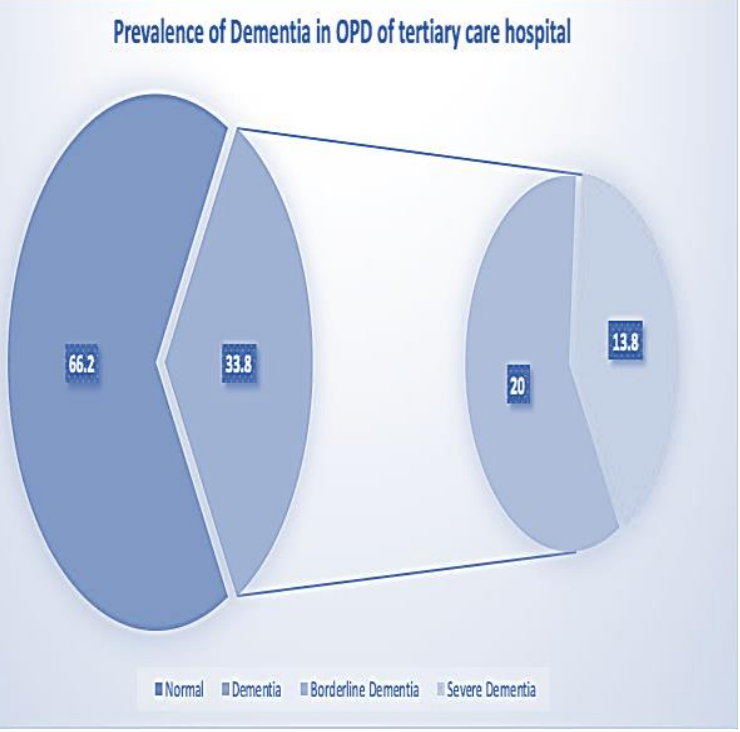

FIGURE 2 ODDS RATIO FOR VARIABLES USED IN MULTIVARIATE REGRESSION

Female

Joint Family

Poor Education Performance

Physical Inactive $<30$ min

Poor Sleep Quality

Depression

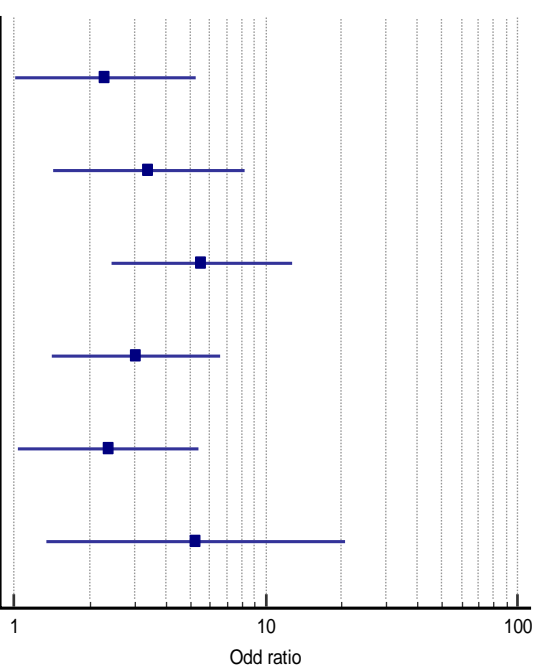

